DOT/FAA/AM-97/17

Office of Aviation Medicine Washington, D.C. 20591

\section{Personality Characteristics of Pre/Post-Strike Air Traffic Control Applicants}

David J. Schroeder

Carolyn S. Dollar

Civil Aeromedical Institute

Federal Aviation Administration

Oklahoma City, Oklahoma 73125

July 1997

Final Report

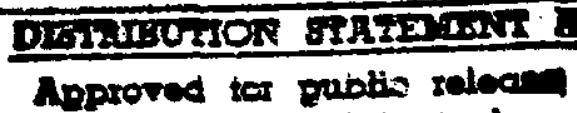

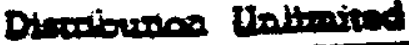

This document is available to the public through the National Technical Information Service, Springfield, Virginia 22161.

U.S. Department of Transportation

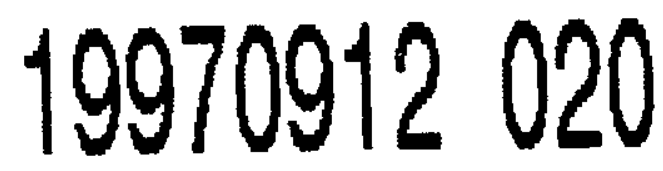

Federal Aviation Administration 


\section{NOTICE}

This document is disseminated under the sponsorship of the U.S. Department of Transportation in the interest of information exchange. The United States Government assumes no liability for the contents or use thereof. 


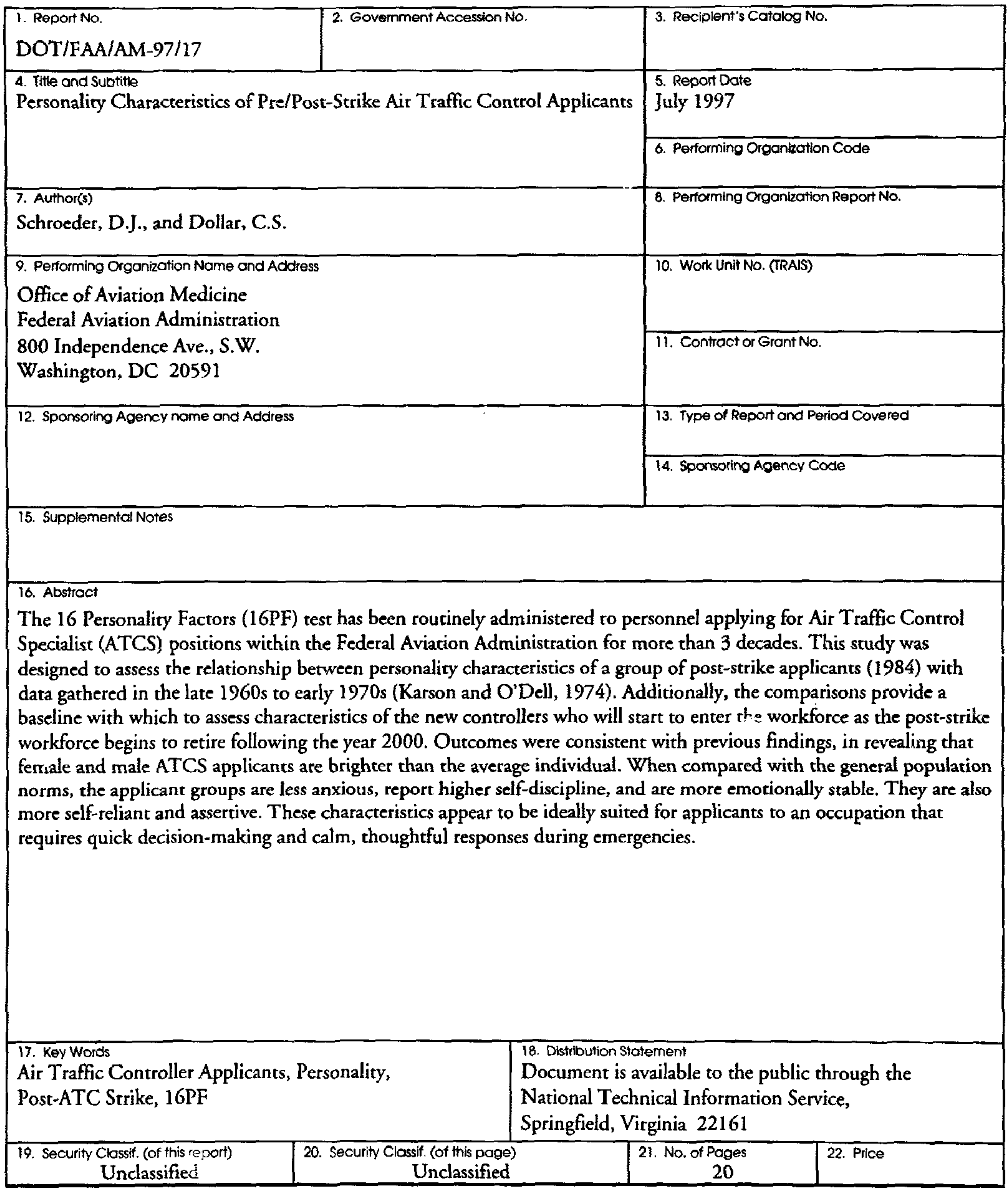

Form DOT F 1700.7 (8-72)

Reproduction of completed page authorized 


\section{Personaltity Characteristics of Pre/Post-Strike Air Traffic Control Applicants}

\section{INTRODUCTION}

Cattell (1949) developed the 16 Personality Factors (16PF) test to measure normal aspects of adult personality. Since the early 1960s, the 16PF has been routinely administered to personnel applying for Air Traffic Control Specialist (ATCS) positions within the Federal Aviation Administration (FAA). The test has been used to identify applicants who may have potential psychological difficulties.

Karson and O'Dell (1974a) reported on the results of a comparison of the personality characteristics between male and female ATCS applicant groups. Since their study, changes in recruitment efforts and selection procedures may have significantly altered the applicant pool. Firings following the air traffic controllers' strike of 1981 created an increased demand for applicants. While recruitment prior to the strike was more often focused on attracting former military air traffic controllers, the post-strike efforts led to increased use of special advertisements and other more active recruitment efforts, including specific attempts to attract more minority and female applicants.

Another post-strike change was the implementation of a new selection battery by the Office of Personnel Management (OPM) in 1981. Both of these changes may have affected the characteristics of the applicant pool. Detailed demographics of ATCS applicants are not available (currently or from Karson and O'Dell, 1974a) however, an analysis of the demo- graphics of personnel who enter training at the FAA Academy is most likely representative of changes in the pool of individuals (applicants) who are eligible for hire.

Table 1 illustrates several significant differences in the demographic composition of Academy entrants in 1968-1970 (Cobb, Matthews, \& Lay, 1972) from those in 1984 and 1985. More of the 1984-85 entrants had a college degree but fewer had previous ATCS experience. The applicant group comprised a greater number or persons under age 30 , and there was also a much higher percentage of females $(14.7 \%$ compared with $2.2 \%$ in 1968-1970). These changes in the demographics of Academy entrants/ATCS applicants may also be reflected in the overall personality profile.

A potential difficulty associated with the interpretation of personality dimensions concerns the influence of response sets on the personality measure. Krug (1978), in commenting on the administration of personality questionnaires to job applicants, and Dolgin and Gibb (1988), in reviewing the relationship between personality measurement and aircrew selection, refer to the role of the "social desirability" response set. This refers to the tendency of applicants to respond in a positive way so as to create a favorable image of themselves. Using an older, and now outdated measure of social desirability, Karson and O'Dell (1974b) found that male ATCS applicants had higher

\section{TABLE 1 - SELECTED DEMOGRAPHICS OF FAA ACADEMY ATCS STUDENTS}

\author{
DEMOGRAPHIC VARIABLE \\ EDUCATION - COLLEGE DEGREE \\ PRIOR EXPERIENCE - ATCS \\ AGE - UNDER 30 \\ GENDER - MALE
}

$\underline{1968-1970}$

$10.1 \%$

$62.2 \%$

$70.4 \%$

$97.8 \%$
1984-1985

$44.9 \%$

$21.0 \%$

$88.8 \%$

$85.3 \%$ 
average scores than a comparison group of journeymen tower controllers (a mean of 6.48 for applicants versus 5.31 for tower controllers). Winder, O'Dell, and Karson (1975) reported on the development of two validity scales for the 16PF: motivational distortion (MD) and fake bad (FB). MD refers to the tendency of the respondent to present him/herself in a favorable light ("fake good"). FB is a measure of the tendency for individuals in certain settings to deliberately present themselves in an unfavorable manner. ("fake bad").

Data analyses were designed to determine if: (a) the personality characteristics of the 1984 ATCS applicant group differed significantly from the Karson and O'Dell (1974a) group, (b) the male and female ATCS applicants in 1984 differed from each other on any of the personality dimensions, (c) the 16PF profiles of applicants and those of the general population and college normative groups were different, and (d) the higher order factor structure for the 1984 16PF scores differed significantly from that reported by Karson and O'Dell (1974a). Profiles were also evaluated to determine the presence of a response set. In addition to providing the above comparisons, data collected from the 1984 group can also serve as a baseline with which to assess characteristics of the new controllers that will start entering the workforce following the year 2000.

\section{METHODS}

Applicants completed the 16PF (1967 version of Forms A and B) following notification of their selection for entrance into the ATCS training program and during their interview at selected sites within each of 9 FAA geographical regions. All of the 1984 16PF records were manually entered into a computerized database.

The sample used in this study was comprised of 3,468 applicants froln $1984,18 \%$ of whom were women. Karson and O'Dell (1974a) reported on results from the administration of the 1962 version of the $16 \mathrm{PF}$ to a sample of 10,103 applicants, of whom $2 \%$ were women.
Raw scores for each of the 16 primary factors (Forms A and B combined) and standard scores (stens) were computed, using the appropriate female or male general population adult norms (IPAT, 1970). In addition to the primary factors, scores were also computed for the two validity scales, $\mathrm{MD}$ and FB. A list of the factors and adjectives typically used to describe high and low scores are contained in Appendix A. (Scale descriptors for the 16 primary personality factors are those used by Krug (1981).) Descriptive statistics included means, standard deviations, and correlations. Differences between the average raw scores on the 16PF for the 1974 and 1984 applicant groups, female and male comparisons for the 1984 sample, and differences between the 1984 applicant groups and the normative groups were determined through use of multiple t-tests based on the pooled variances of the groups. Risk of Type 1 errors for the multiple comparisons was minimized through the use of Dunn's test (Howell, 1987).

The large sample sizes resulted in a number of statistically significant differences that were of limited practical significance. Cohen's (1988) index of effect size (d) was used to determine which of the differences were of practical significance. Only differences with a medium effect size (.50) or greater are discussed in this report. A second measure of practical significance, the Common Language Effect Sizes ( $C L$; McGraw \& Wong, 1992) was also used. The $C L$ measures the significance of any difference based on the number of times out of 100 that a randomly selected entry-level controller will have a higher score on a given personality scale than a randomly selected person from the general population or from one of the other controller groups. For example, a CL of 75 on the Warmth scale means that, for any random pairing of a controller with a member of the general, normative population, the controller would have a higher score 3 out of 4 times. For the purposes of this study CL levels of $>70$ and $<30$ were selected as providing evidence of a practical difference between the 1984 ATCS applicants and comparison groups. 
Results from this study were submitted to a factor analytic procedure similar to that used by Karson and O'Dell (1974a); an oblim rotation forcing the 16PF variables into 6 factors. A program developed by Hebbler (1989) was used to determine the coefficients of concordance for the female and male 1974 and 1984 comparisons and for comparing the $1984 \mathrm{fe}$ male-male outcomes.

\section{RESULTS}

1974 and 1984 Female Comparisons. Raw score means, standard deviations, and effect sizes ( $d$ and CL) of 16PF scores for female ATCS applicants from this study and those from Karson and O'Dell (1974a) are presented in Table 2 . Differences in the average scores for 11 of the 16 factors were statistically significant ( $p<.01)$. Differences for the Warmth, Intelligence, Conformity, Suspiciousness, and Shrewdness factors were not significant. Differences for the Emotional Stability, Dominance, Boldness, Insccurity,
Radicalism, Self-sufficiency, and Self-Discipline factors had medium or larger effect sizes. Of those with significant $t$ values and effect sizes (d), only the Dominance, Radicalism, Self-Sufficiency, and SelfDiscipline comparisons had CL values in the designated ranges ( $C L$ of $>70$ c $<30$ ). Female applicants in 1984 exhibited higher scores on the measures of Emotional Stability, Dominance, Boldness, and SelfDiscipline than their counterparts in 1974. Compared with the Karson and O'Dell (1974a) sample, they are significantly lower in Insecurity, Radicalism, and Self-Sufficiency.

Thus, female applicants in 1984 are less anxious and insecure and appear to have greater resources to cope with anxiety when it does arise. They also appeared more self-assertive, adventuresome, independent, and imaginative than the 1974 female applicants.

Results of the 1984 factor analysis of the female 16PF scores were similar to those noted by Karson and O'Dell (1974a). The higher-order factors correspond to what Karson and O'Dell (1974a) called: Anxiety,

\section{TABLE 2 - 16PF FORM A + B RAW SCORE MEANS AND STANDARD DEVIATIONS FOR 1974 AND 1984 FEMALE ATCS APPLICANTS}

$\begin{array}{ll} & \text { FACTOR } \\ \text { A } & \text { (WARMTH) } \\ \text { B } & \text { (INTELLIGENCE) } \\ \text { C } & \text { (EMOTIONAL STABILITY) } \\ \text { E } & \text { (DOMINANCE) } \\ \text { F } & \text { (IMPULSIVITY) } \\ \text { G } & \text { (CONFORMITY) } \\ \text { H } & \text { (BOLDNESS) } \\ \text { I } & \text { (SENSITIVITY) } \\ \text { L } & \text { (SUSPICIOUSNESS) } \\ \text { M } & \text { (IMAGINATION) } \\ \text { N } & \text { (SHREWDNESS) } \\ \text { O } & \text { (INSECURITY } \\ \text { Q1 } & \text { (RADICALISM) } \\ \text { Q2 } & \text { (SELF-SUFFICIENCY) } \\ \text { Q3 } & \text { (SELF-DISCIPLINE) } \\ \text { Q4 } & \text { (TENSION) } \\ \text { MD } & \text { (DISTORTION) } \\ \text { FB } & \text { (FAKE BAD) }\end{array}$

$p \leq .01$

d. .50 or higher for medium effect size

$\mathrm{CL}>70$ or $<30$
$1974(\mathrm{~N}=217)$

\begin{tabular}{|c|c|}
\hline $\begin{array}{l}\text { MEAN } \\
18.82 \\
17.65 \\
37.57 \\
20.38 \\
28.63 \\
31.03 \\
30.17 \\
19.59 \\
12.59 \\
21.23 \\
22.02 \\
16.00 \\
20.38 \\
21.55 \\
26.32 \\
16.63\end{array}$ & $\begin{array}{l}\frac{S D}{6.37} \\
2.42 \\
6.94 \\
5.94 \\
7.76 \\
4.69 \\
9.50 \\
5.59 \\
4.74 \\
5.59 \\
3.39 \\
6.40 \\
4.02 \\
5.30 \\
4.78 \\
8.33\end{array}$ \\
\hline
\end{tabular}

$1984(\mathrm{~N}=624)$

MEAN SD

$18.98 \quad 6.14$

$17.88 \quad 2.75$

40.72

25.64

31.38

30.51

35.51

21.54

11.45

23.63

21.27

12.36

17.08

16.91

30.62

13.91

8.20

6.27

6.27

6.93

4.84

9.70

5.23

4.87

5.10

4.65

6.62

4.79

5.53

4.71

8.67

3.00

$0.91 \quad 1.10$

$\begin{array}{ccc}\underline{t} & \underline{\mathbf{d}} & \mathbf{C L} \\ -0.32 & .03 & \mathbf{4 9} \\ -1.16 & .08 & 48 \\ -5.89^{*} & .50 & 37 \\ -11.05^{*} & .84 & 27 \\ -4.61^{*} & .40 & 40 \\ 1.39 & .10 & 53 \\ -7.08^{*} & .55 & 35 \\ -4.49^{*} & .37 & 40 \\ 3.02 & .23 & 57 \\ -5.56^{*} & .47 & 37 \\ 2.30 & .16 & 35 \\ 7.14^{*} & .55 & 66 \\ 9.88^{*} & .69 & 70 \\ 10.96^{*} & .84 & 73 \\ -11.44^{*} & .91 & 26 \\ 4.09^{*} & .31 & 59\end{array}$


Extroversion, Independence, Cortical Alertness, Obsessive-Compulsivity, and Intelligence, which primarily involved a single scale (B). However, Extroversion and Independence (the second and third factors in 1974) reversed order to become the third and second factors in the 1984 sample. Using a program developed by Hebbler (1989), coefficients of concordance were determined to compare the factor solutions from the two samples. Provided the order of the factors is adjusted for the differences noted above, the coefficients of concordance for the comparisons; .91, $.93, .86, .86, .92$, and .94 suggest that the underlying factor structure is highly similar.

1974 and 1984 Male Comparisons. Raw score means, standard deviations, and effect sizes of the scores on the 16PF for male ATCS applicants in 1984 and from the Karson and O'Dell (1974a) study are presented in Table 3. All differences in the average scores for the 16 comparisons were statistically significant $(\mathrm{p}<.01)$.
Six differences in the factor scores were of medium effect size or greater. Male ATCS applicants in 1984 had higher scores on the Emotional Stability, Dominance, Imagination, and Self-Discipline factors than those in the Karson and O'Dell (1974a) study. Their average 16PF scores were lower on the Insecurity and Radicalism factors. Of these comparisons, only Dominance, Imagination, Radicalism, and Self-Discipline had $C L$ values in the prescribed ranges.

The general pattern of differences in the $16 \mathrm{PF}$ from 1974 to 1984 for men was quite similar to those noted for women: less tension and insecurity, along with greater self-assertiveness, self-discipline, and emotional stability. 1984 applicants clearly report less anxiety and appear to have greater resources to cope with anxiety than 1974 applicants.

Comparisons of the 1984 factor analysis of the 16PF scores for male ATCS applicants with that of Karson and O'Dell (1974a) were identical to that noted for females. Once again, the order for factors

TABLE 3 - 16PF FORM A + B RAW SCORE MEANS AND STANDARD DEVIATIONS FOR 1974 AND 1984 MALE ATCS APPLICANTS

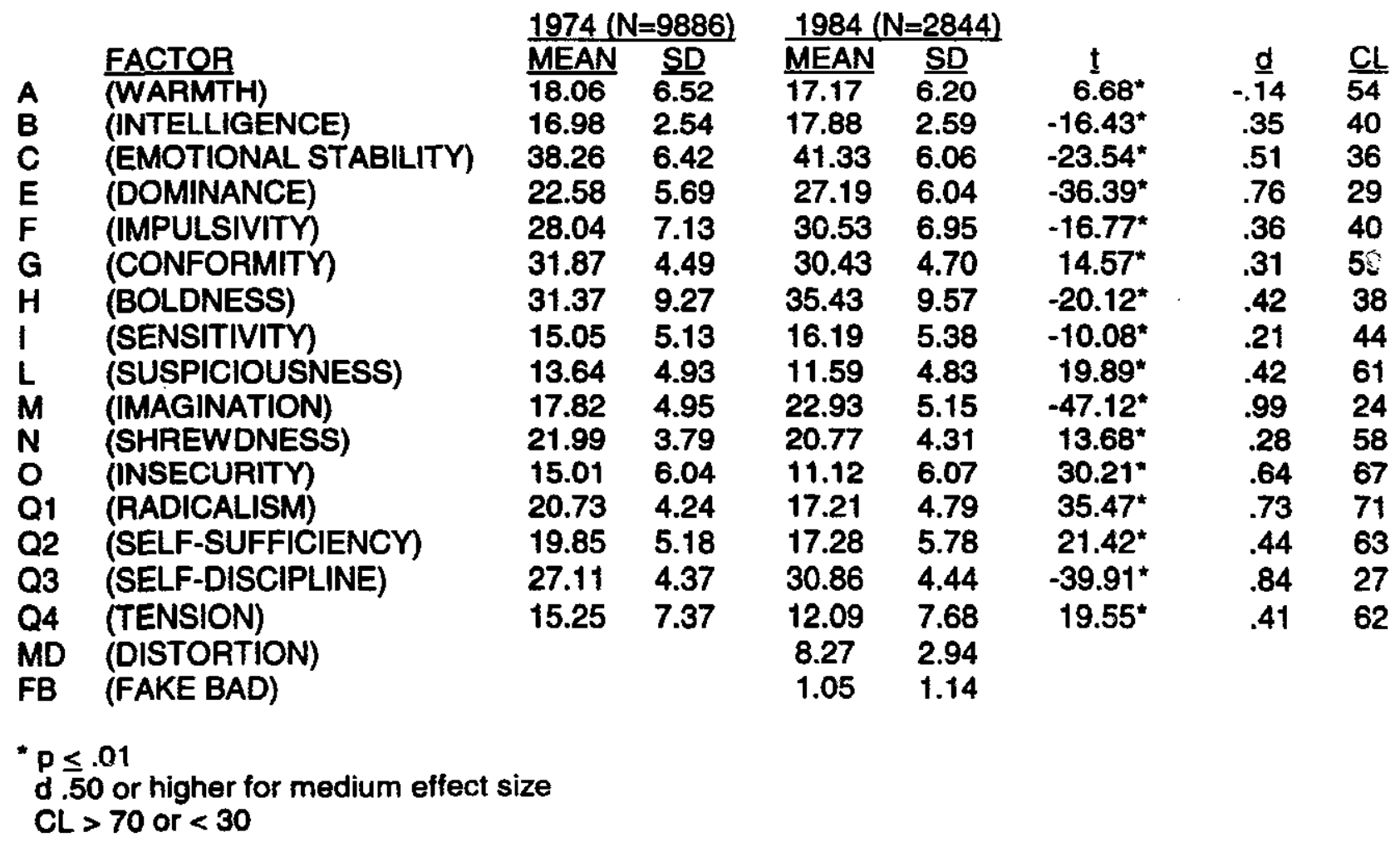


two and three was reversed for the 1984 sample. Coefficients of concordance (following reversal of the two factors) yielded rates consistent with those noted for females: $.92, .96, .77, .97, .71$, and .98 for each of the 6 higher order factors. Thus, despite differences in the overall profile between the two samples, the underlying factor structure has remained generally stable.

1984 Male and Female Comparisons. Table 4 illustrates the raw score means, standard deviations, and effect sizes for the male and female ATCS applicants in 1984. While 5 of the comparisons reached statistical significance, only the difference on the Sensitivity factor had a medium or greater effect size (d and $\mathrm{CL}$ ). These results are consistent with those of Karson and O'Dell (1974a) in revealing little difference between the personality profiles of male and fernale ATCS applicants. Results are also generally consistent with those of a recent meta-analysis of gender differences in personality conducted by Feingold (1994). He reported that when compared with men, women exhibited higher scores on scales measuring extroversion, anxiety, trust, and tendermindedness.

Outcomes for the factor analysis of the 1984 male and female results are presented in Table 5, along with the respective coefficients of concordance. The factor structure for the $\mathbf{2}$ groups was essentially identical, with the coefficients of concordance ranging from .91 for the cortical alertness factor to .99 for anxiety, extroversion, and compulsivity.

Comparisons of 1984 Female ATCS Applicants With the General Population and College Norms. Average 16PF profiles for the 1984 female ATCS applicants and the general population normative sample are presented in Table 6. Female ATCS applicants were significantly different from the normative group on 13 of the 16 factors. Differences on the Imagination, Shrewdness, and Radicalism factors were not significant. Differences in the average factor scores that had a medium effect size or greater included the

\section{TABLE 4 - 16PF FORM A + B RAW SCORE MEANS ANO STANDARD -DEVIATICNS FOR 1984 FEMALE AND MALE ATCS APPLICANTS}

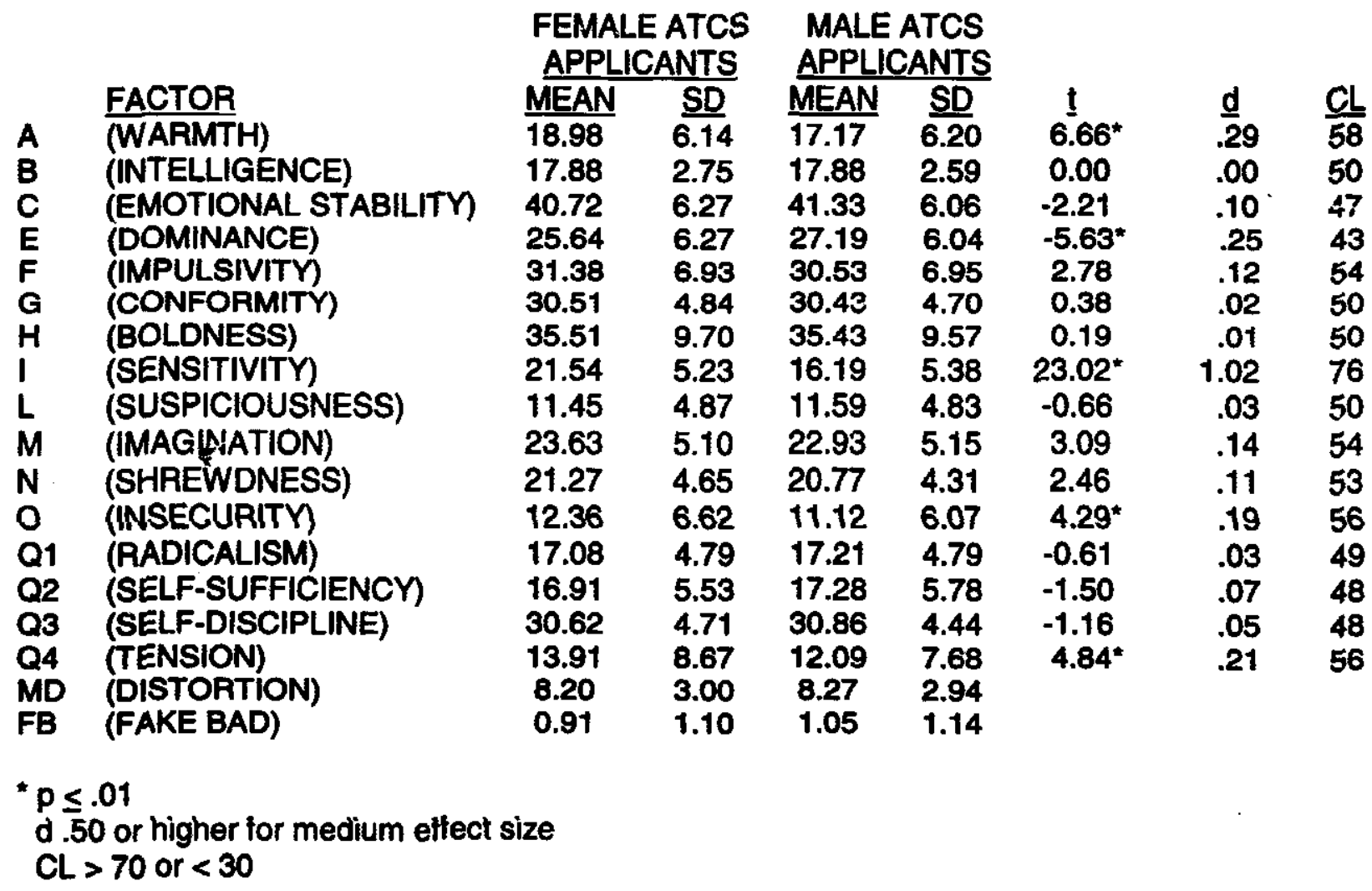




\begin{tabular}{|c|c|c|c|c|c|c|c|c|c|c|c|c|c|}
\hline & \multicolumn{12}{|c|}{ FACTOR } \\
\hline & & \multicolumn{2}{|c|}{ Anxiety } & \multicolumn{2}{|c|}{ Independence } & \multicolumn{2}{|c|}{ Extroversion } & \multicolumn{2}{|c|}{$\begin{array}{l}\text { Cortical } \\
\text { Alentness }\end{array}$} & \multicolumn{2}{|c|}{$\begin{array}{l}\text { Obsessive- } \\
\text { Compulsivity }\end{array}$} & \multicolumn{2}{|c|}{ Intelligence } \\
\hline & & \multicolumn{2}{|c|}{1} & \multicolumn{2}{|c|}{ II } & \multicolumn{2}{|r|}{ IIII } & \multicolumn{2}{|c|}{ IV } & \multicolumn{2}{|r|}{ V } & \multicolumn{2}{|r|}{ VI } \\
\hline & & $\frac{M}{-02}$ & $\frac{F}{.03}$ & $\frac{M}{.03}$ & $\frac{F}{-01}$ & $\frac{\bar{M}}{76}$ & $\frac{F}{73}$ & $\frac{\bar{M}}{26}$ & $\frac{F}{26}$ & $\frac{\bar{M}}{12}$ & $\frac{F}{14}$ & $\frac{\bar{M}}{06}$ & $\frac{F}{-08}$ \\
\hline B & (Intelligence) & 01 & 01 & 01 & -01 & 04 & -01 & -06 & 00 & 03 & 13 & 100 & 100 \\
\hline 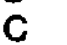 & (Emotional Stability) & 86 & 87 & .01 & 05 & 06 & 03 & -05 & .07 & 05 & 02 & 02 & 05 \\
\hline ᄃ & (Dominance) & -01 & -19 & 80 & 63 & 16 & 17 & -14 & -37 & 04 & -03 & -06 & -05 \\
\hline $\mathbf{F}$ & (Impulsivity) & -02 & -13 & 27 & 15 & 69 & 71 & -14 & -11 & -29 & -27 & -06 & 02 \\
\hline G & (Conformity) & -08 & -09 & 01 & 00 & 12 & 08 & -00 & 00 & 90 & 91 & -00 & 06 \\
\hline$H$ & (Boldness) & 42 & 37 & 26 & 26 & 58 & 61 & 00 & -17 & 16 & 13 & .05 & -04 \\
\hline I & (Sensitivity) & -16 & -19 & -10 & 07 & 18 & 12 & 90 & 90 & 06 & -00 & -02 & -03 \\
\hline $\mathbf{L}$ & (Suspiciousness) & -77 & -83 & 38 & 27 & -02 & -02 & -11 & -03 & 15 & 17 & -05 & -08 \\
\hline$M$ & (Imagination) & 31 & 34 & 46 & 68 & -16 & -10 & 55 & 26 & -20 & -23 & 03 & 12 \\
\hline $\mathbf{N}$ & (Shrewdness) & 20 & 25 & -48 & -29 & -14 & -11 & 10 & 25 & 28 & 33 & -06 & -21 \\
\hline 0 & (Insecurity) & -81 & -80 & -20 & -22 & -13 & -13 & 09 & 09 & -08 & -08 & -03 & 01 \\
\hline Q1 & (Radicalism) & -01 & -03 & 74 & 76 & -12 & -04 & 11 & -01 & 01 & 08 & 11 & 05 \\
\hline Q2 & (Self-Sufficiency) & -12 & -14 & 18 & 29 & -79 & -80 & 03 & -01 & -05 & -05 & 05 & -03 \\
\hline Q3 & (Self-Discipline) & 40 & 50 & 03 & 05 & -13 & -12 & -01 & -04 & 68 & 58 & -00 & -04 \\
\hline Q & (Tension) & -82 & -83 & -01 & -08 & -01 & -00 & 02 & 07 & -19 & -16 & 05 & 11 \\
\hline & icient of Concordance & & 99 & & 5 & & & & & & 9 & & 96 \\
\hline
\end{tabular}

factors of Warmth, Intelligence, Emotional Stability, Dominance, Impulsivity, Conformity, Boldness, Sensitivity, Suspiciousness, Insecurity, Self-Discipline, and Tension. CL levels again appeared to be somewhat more conservative in that only 8 out of the 11 comparisons that had significant d values also had CL values in the designated ranges.

Female ATCS applicants, when compared with fernales in the general population, are more intelligent, emotionally stable, and assertive. They are also more enthusiastic, venturesome, and have greater selfconfidence and self-control. Their self-reported level of tension or anxiety is clearly lower than that of the average woman; ATCS applicants are also less insecure and sensitive.

Table 7 illustrates the raw score means, standard deviarions, and effect sizes of the female ATCS applicants and those of the female college student normative group. Differences between the ATCS applicant group and the college student group were similar to differences between the applicants and the general population. Average scores on the Intelligence factor are an exception, with the female ATCS applicant mean score (17.88) only slightly higher than that of college students (17.50). Female college students (33.32) are more impulsive than the general population (26.57) and, to a lesser extent, more impulsive than ATCS applicants (31.38). For several factors, the spread of scores across the groups was somewhat greater. On the Tension factor, ATCS applicants had a mean factor score of only 13.91, compared with 25.96 for the general population and 28.26 for college students. Of the ATCS applicant-college student comparisons with significant $t$ scores, all but 4 were of medium or greater d value. A smaller number reached the appropriate ranges for a significant $\mathrm{CL}$ level.

Comparisons of 1984 Male ATCS Applicants With the General Population and College Norms. Raw score means, standard deviations and effect sizes of the 1984 male ATCS applicants and normative male data for the $16 \mathrm{PF}$ are presented in Table 8 . Male ATCS applicants were significantly different from the normative group on 15 of the factors; the difference on the Dominance factor was not significant. Considering only those differences that met the effect size criterion, male ATCS's are like the general population males on about half of the 16PF factors. Male ATCS applicants are less outgoing, suspicious, insecure, 
TABLE 6 - 16PF FORM A + B RAW SCORE MEANS AND STANDARD DEVIATIONS FOR 1984 FEMALE ATCS APPLICANTS AND FEMALE GENERAL POPULATION

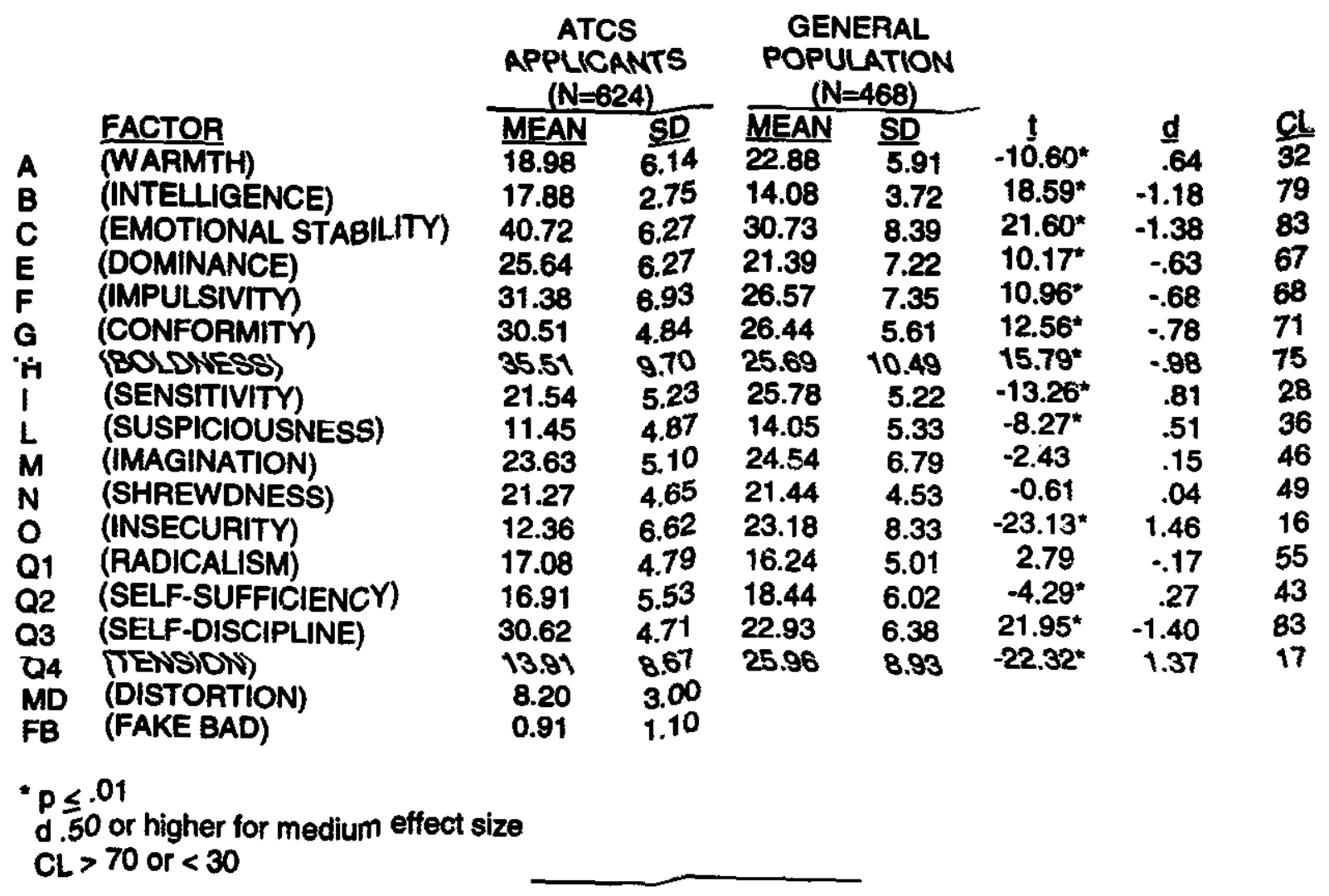

TABLE 7 - 16PF FORM A + B RAW SCORE MEANS AND STANDARD DEVIATIONS FOR 1984 FEMALE ATCS APPLICANTS AND FEMALE COLLEGE STUDENTS

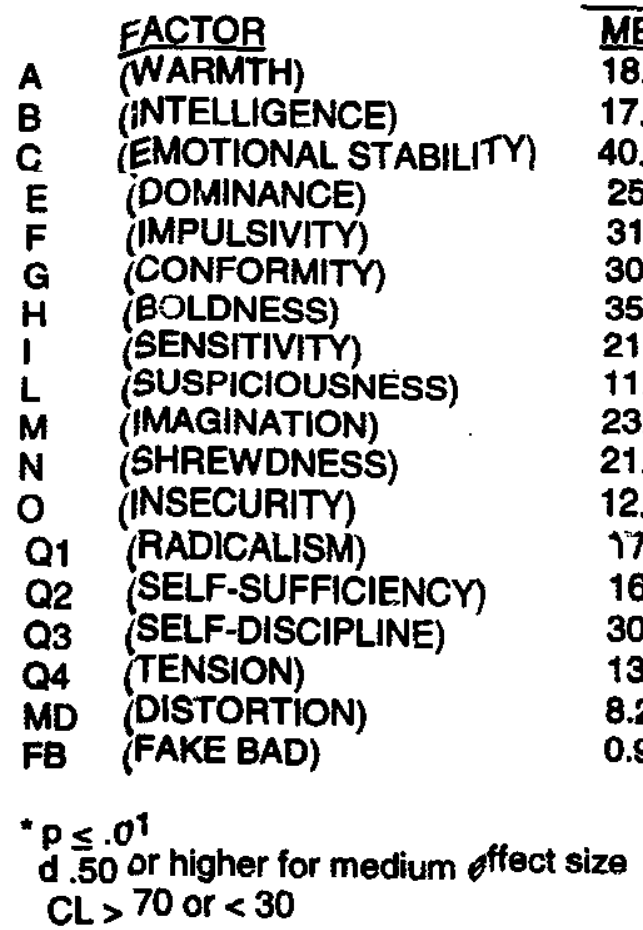

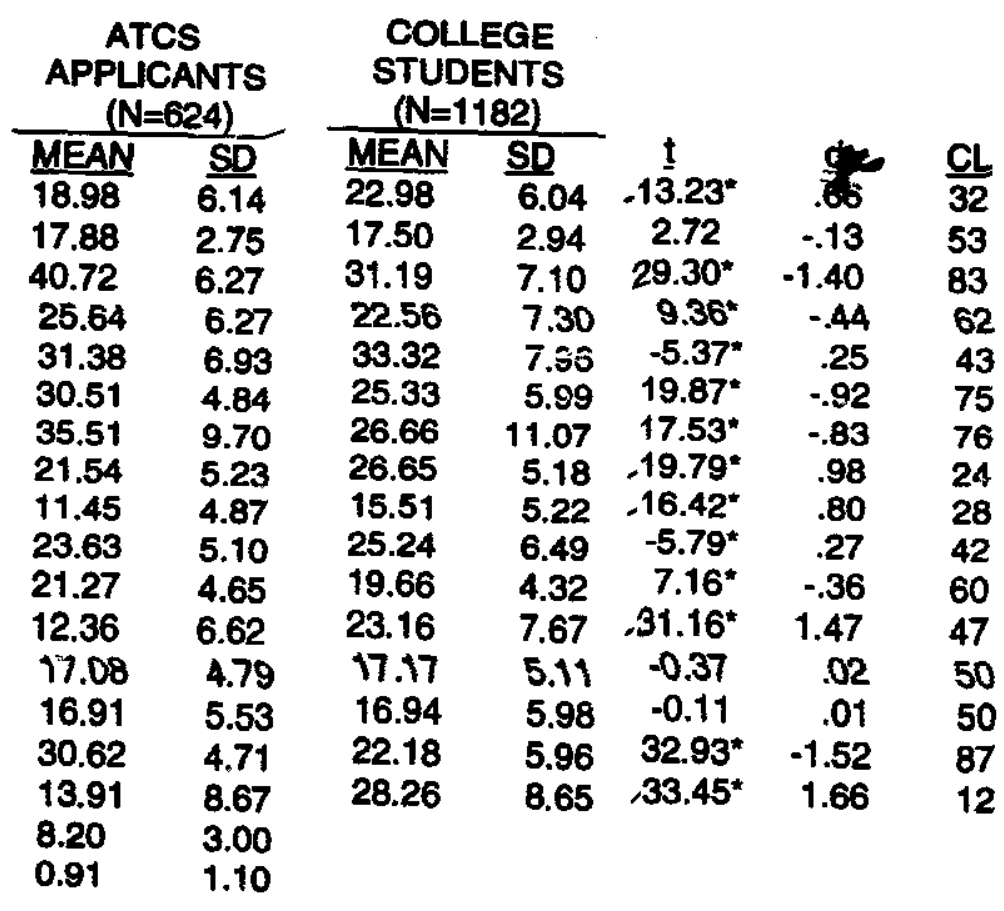




\section{TABLE 8 - 16PF FORM A + B RAW SCORE MEANS AND STANDARD DEVIATIONS FOR 1984 MALE ATCS APPLICANTS AND MALE GENERAL POPULATION}

\begin{tabular}{|c|c|c|c|c|c|c|c|c|}
\hline & & $\begin{array}{r}\text { AT } \\
\text { APPL } \\
(\mathrm{N}=2\end{array}$ & $\begin{array}{l}\text { NTS } \\
\text { 4) }\end{array}$ & $\begin{array}{r}\text { GE } \\
\text { POPI } \\
(\mathrm{N}\end{array}$ & $\begin{array}{l}\text { RAL } \\
\text { ITION } \\
\text { 42) }\end{array}$ & & & \\
\hline A & $\frac{\text { FACTOR }}{\text { (WARMTH) }}$ & $\frac{\text { MEAN }}{17.17}$ & $\frac{\mathrm{SD}}{6.20}$ & $\frac{\text { MEAN }}{20.36}$ & $\frac{S D}{6.32}$ & $\stackrel{t}{t}$ & $\frac{\mathrm{d}}{51}$ & $\frac{\mathrm{CL}}{36}$ \\
\hline $\mathrm{B}$ & (INTELLIGENCE) & 17.88 & 2.59 & 14.08 & 3.72 & $32.71^{*}$ & -1.28 & 81 \\
\hline C & (EMOTIONAL STAB!LITY) & 41.33 & 6.06 & 34.69 & 8.18 & $25.69^{*}$ & -.98 & 74 \\
\hline $\mathbf{E}$ & (DOMINANCE) & 27.19 & 6.04 & 26.71 & 6.37 & 2.25 & -.08 & 52 \\
\hline$\vec{F}$ & (IMPULSIVITY) & 30.53 & 6.95 & 28.40 & 7.45 & $8.58^{*}$ & -.30 & 58 \\
\hline $\mathbf{G}$ & (CONFORMITY) & 30.43 & 4.70 & 26.88 & 5.78 & $19.07^{\star}$ & -.70 & 68 \\
\hline$H$ & (BOLDNESS) & 35.43 & 9.57 & 30.30 & 10.26 & $15.01^{*}$ & -.52 & 64 \\
\hline I & (SENSITIVITY) & 16.19 & 5.38 & 18.25 & 5.75 & $-10.74^{*}$ & .37 & 40 \\
\hline$L$ & (SUSPICIOUSNESS) & 11.59 & 4.83 & 14.78 & 5.48 & $-17.73^{*}$ & .63 & 33 \\
\hline $\mathbf{M}$ & (IMAGINATION) & 22.93 & 5.15 & 25.86 & 6.36 & $-14.32^{*}$ & .53 & 36 \\
\hline $\mathbf{N}$ & (SHREWDNESS) & 20.77 & 4.31 & 19.76 & 4.37 & $6.83^{*}$ & -.23 & 56 \\
\hline 0 & (INSECURITY) & 11.12 & 6.07 & 17.60 & 8.49 & $-24.32^{*}$ & .94 & 27 \\
\hline Q1 & (RADICALISM) & 17.21 & 4.79 & 18.20 & 4.88 & $-6.00^{*}$ & .20 & 44 \\
\hline Q2 & (SELF-SUFFICIENCY) & 17.28 & 5.78 & 18.25 & 5.78 & $-4.94^{*}$ & .17 & 45 \\
\hline Q3 & (SELF-DISCIPLINE) & 30.86 & 4.44 & 25.24 & 6.01 & $29.62^{*}$ & -1.13 & 77 \\
\hline Q4 & (TENSION) & 12.09 & 7.68 & 20.61 & 9.41 & $-28.09^{*}$ & 1.03 & 24 \\
\hline MD & (DISTORTION) & 8.27 & 2.94 & & & & & \\
\hline FB & (FAKE BAD) & 1.05 & 1.14 & & & & & \\
\hline
\end{tabular}

imaginative, and tense than other men. They also have higher scores on factors measuring Intelligence, Emotional Stability, Conformity, Boldness, and Self-Discipline.

Thus, ATCS men, in contrast to men in the general population norms, are brighter, experience less anxiety, and have greater resources to cope with stress. Furthermore, they are more adventuresome, assertive, self-disciplined, and self-assured. Differences in the factor scores of the female and male ATCS applicants from the general population 16PF norms are illustrated in Figure 1.

Data presented in Table 9 compare the results of the 1984 male ATCS applicant group with normative data from male college students. In most cases, the differences noted between male ATCS applicants and the general population are also true between those ATCSs and college students. Average scores for the Intelligence and Impulsivity factors are 2 exceptions.
The 1984 ATCS applicant mean (17.88) on Intelligence is only slightly above that of college students (17.50). The college student mean for Impulsivity (32.34) is above that of both ATCS applicants (30.53) and the general population (28.40). While most of the ATCS applicants have attended college, they differ from the normative college group in that applicants report less suspiciousness, radicalism, and considerably less insecurity and anxiety. They also are more emotionally stable and have greater self-discipline. Differences discussed above are evident in comparing 16PF profile elevations for the female and male ATCS applicant groups and are shown in Figure 2.

Validity Scale Comparisons. While average MD scores of 1984 male and female ATCS applicants were nearly identical (8.20 for females and 8.27 for males), they were clearly above the average value (6.06) for the general population (Krug, 1978). In his validation study of the MD scale, Krug reported average 
FIGURE 1 -1984 APPLICANT 16PF PROFILE - GENERAL POPULATION NORMS STANDARD SCORE (STEN)

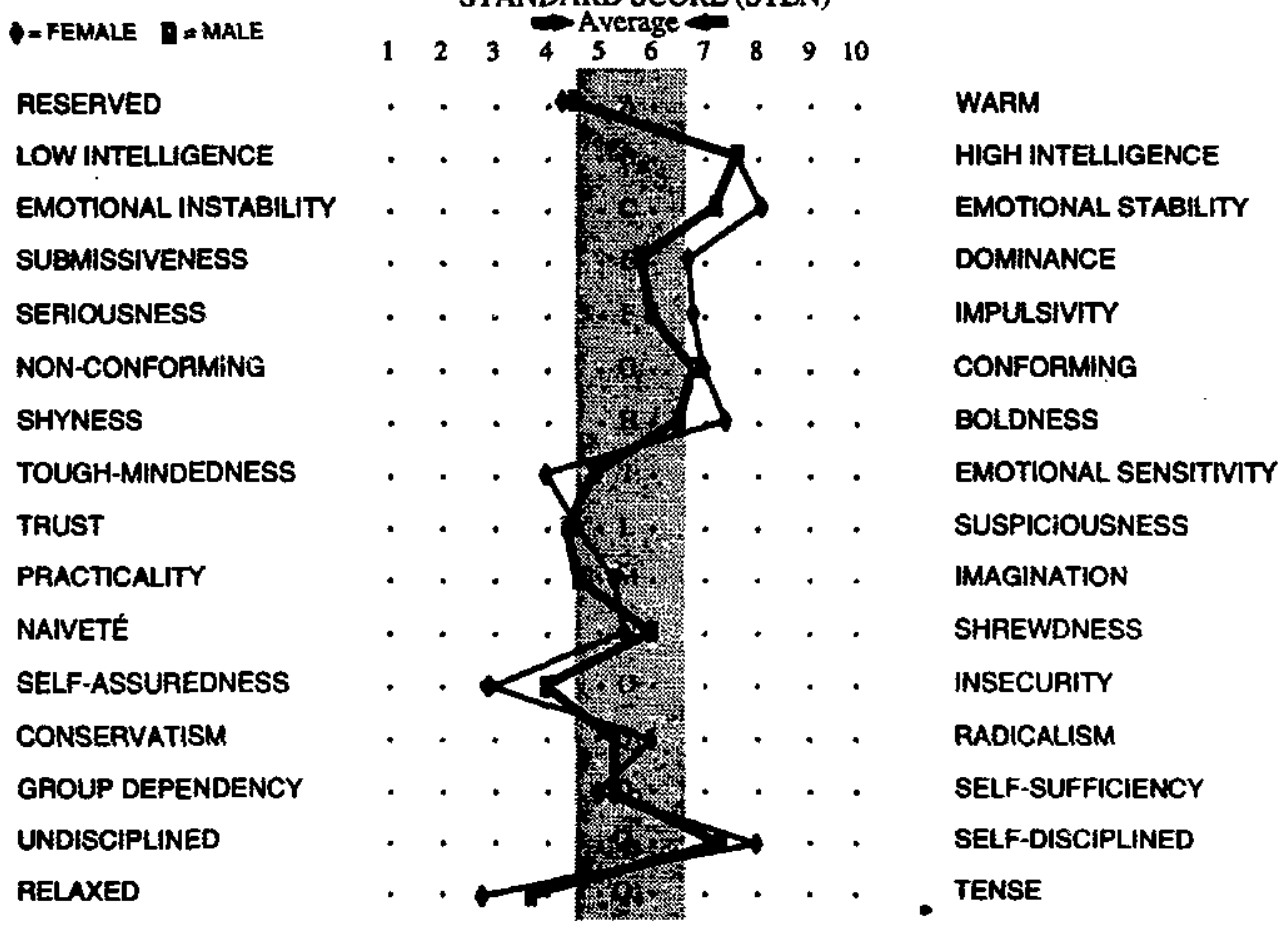

TABLE 9 - 16PF FORM A + B RAW SCORE MEANS AND STANDARD DEVIATIONS FOR 1984 MALE ATCS APPLICANTS AND MALE COLLEGE STUDENTS

$\begin{array}{ll} & \text { FACTOR } \\ \text { A } & \text { (WARMTH) } \\ \text { B } & \text { (INTELLIGENCE) } \\ \text { C } & \text { (EMOTIONAL STABILITY) } \\ \text { E } & \text { (DOMINANCE) } \\ \text { F } & \text { (IMPULSIVITY) } \\ \text { G } & \text { (EONFORMITY) } \\ \text { H } & \text { (BOLDNESS) } \\ \text { I } & \text { (SENSITIVITY) } \\ \text { L } & \text { (SUSPICIOUSNESS) } \\ \text { M } & \text { (IMAGINATION) } \\ \text { N } & \text { (SHREWDNESS) } \\ \text { O } & \text { (INSECURITY) } \\ \text { Q1 } & \text { (RADICALISM) } \\ \text { Q2 } & \text { (SELF-SUFFICIENCY) } \\ \text { Q3 } & \text { (SELF-DISCIPLINE) } \\ \text { Q4 } & \text { (TENSION) } \\ \text { MD } & \text { (DISTORTION) } \\ \text { FB } & \text { (FAKE BAD) }\end{array}$

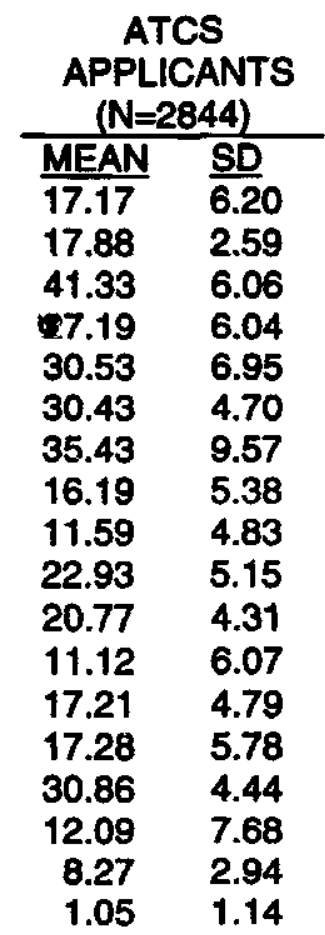

COLLEGE STUDENTS

\begin{tabular}{|c|c|c|c|c|}
\hline \multicolumn{2}{|c|}{$(\mathrm{N}=1517)$} & \multirow{3}{*}{$-12.02^{t}$} & \multirow{3}{*}{$\frac{d}{39}$} & \multirow{3}{*}{$\frac{\mathrm{Cl}}{40}$} \\
\hline MEAN & SD & & & \\
\hline 19.72 & 6.92 & & & \\
\hline 17.50 & 2.94 & $4.24^{*}$ & -.14 & 54 \\
\hline 31.36 & 7.19 & $46.02^{*}$ & -1.54 & 8 \\
\hline 27.89 & 7.11 & $-3.26^{\star}$ & .11 & 47 \\
\hline 32.34 & 8.28 & $-7.26^{\star}$ & .24 & 44 \\
\hline 24.27 & 6.25 & $33.66^{*}$ & -1.16 & 79 \\
\hline 27.45 & 10.96 & $23.92^{*}$ & -.79 & 71 \\
\hline 17.71 & 6.46 & $-7.83^{*}$ & .26 & 43 \\
\hline 17.83 & 5.19 & $-38.76^{*}$ & 1.26 & 19 \\
\hline 24.79 & 6.79 & $-9.34^{\star}$ & .32 & 41 \\
\hline 17.80 & 4.26 & $21.85^{*}$ & -.69 & 69 \\
\hline 20.57 & 7.91 & $-40.61^{*}$ & 1.40 & 17 \\
\hline 19.91 & 5.26 & $-16.66^{*}$ & .54 & 35 \\
\hline 18.30 & 6.26 & $-5.27^{\star}$ & .17 & 45 \\
\hline 22.64 & 5.60 & $49.49^{*}$ & -1.69 & 87 \\
\hline 25.75 & 8.63 & $-51.72^{*}$ & 1.70 & \\
\hline
\end{tabular}

${ }^{\star} p \leq .01$

d .50 or higher for medium effect size

$\mathrm{CL}>70$ or $<30$ 


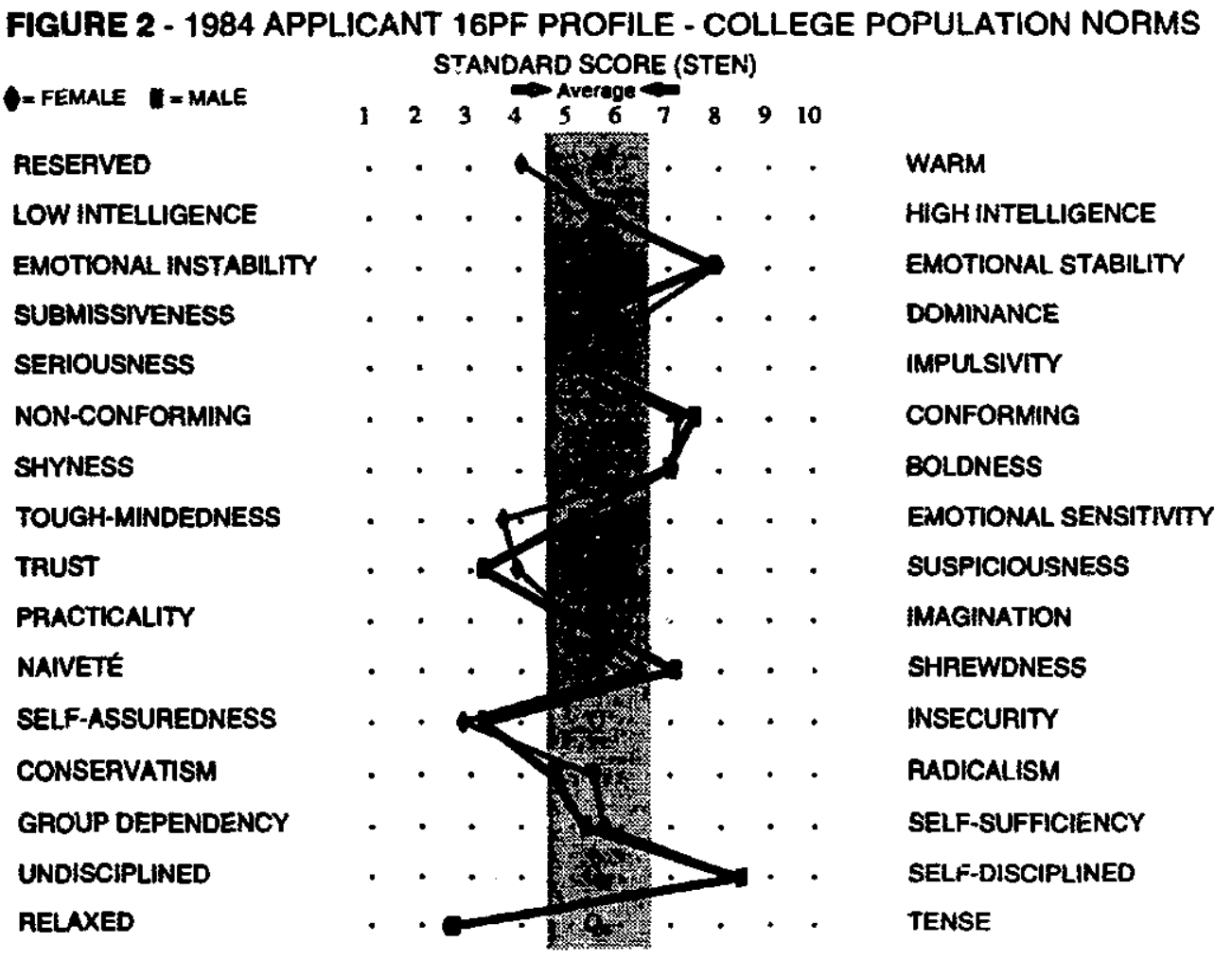

scores of 5.71 for females and 6.36 for males, and recomm nded using a raw score of 10 as the criterion for determining when the overall 16PF profile may be unduly influenced by an individual's attempt to present $\mathrm{him} /$ herself in a favorable light. Distributions of MD scores for female and male ATCS applicants, as well as for the sample from Krug (1978), are presented in Table 10. Comparisons of the male and female ATCS distributions with that of Krug (1978) reveal the skewed nature of the applicant responses for both the $\mathrm{MD}$ and FB measures. Using Krug's (1978) criterion, responses for $33.0 \%$ of the female and $35.2 \%$ of the male ATCS applicants suggested the presence of a "Fake Good" response set. Krug (1978) found that only $12.5 \%$ of the overall group met that criterion. $M$. Rieke (personal communication, February 1, 1994) suggests that Krug's cutoff for the MD is too low and should be closer to two standard deviations above the mean, corresponding to a sten of 9 . Even with this higher critesion, approximately $24 \%$ of the women and men scored above the cutoff.

As could be expected, given the high MD scores, there was little evidence of any "Faking Bad" on the 16PF for the ATCS applicants. The average FB scores for ATCS applicants (0.91 for females and 1.05 for males) were clearly below the average of 2.82 reported for the general population norms. Using the criterion of a raw score of 6 or higher (Krug, 1978), only $0.5 \%$ of each of the female and male ATCS applicants were in the "Fake Bad" range.

Correlations between the validity scales and the 16PF primary factors are presented in Table 11. Consistent with Krug's (1978) results, MD scores are most closely related to the Emotional Stability, Conformity, Boldness, Suspiciousness, Insecurity, Self-Discipline, and Tension factors. Individuals who attempt to present themselves in a positive light on the $16 \mathrm{PF}$ will report less tension, insecurity, and suspiciousness, and greater emotional stability, conformity; boldness, and self-discipline. It is noteworthy that, on many of these same factors, female and male ATCS groups differ most from their respective normative groups. Correlations between the FB scores and the 16 primary faciuts were relatively low. The highest correlations were within the .22 to .27 range. FB was negatively correlated with Emotional Stability, Boldness, and Self-Discipline. Positive correlations were evident between FB and scores on the Suspiciousness, Insecurity, Self-Sufficiency, and Tension factors. 
TABLE 10 - PERCENTAGES OF VALIDITY SCALE

SCORES FOR FEMALE AND MALE ATCS APPLICANTS

\begin{tabular}{|c|c|c|c|c|c|c|c|c|}
\hline \multirow{3}{*}{$\begin{array}{c}\text { RAW } \\
\text { SCORE }\end{array}$} & \multicolumn{4}{|c|}{ FAKE GOOD (MD) } & \multicolumn{4}{|c|}{ FAKE BAD (FB) } \\
\hline & \multicolumn{2}{|c|}{ ATCS $\%$} & \multicolumn{2}{|c|}{ KRUG 1978} & \multicolumn{2}{|c|}{ ATCS $\%$} & \multicolumn{2}{|c|}{ KRUG 1978} \\
\hline & FEMALE & MALE & STEN & PERCENT & FEMALE & MALE & STEN & PERCENT \\
\hline 0 & 0.2 & 0.1 & 1 & 0.0 & 43.8 & 37.3 & 1 & 19.7 \\
\hline 1 & 0.3 & 0.5 & 2 & 3.7 & 34.0 & 36.6 & 2 & 24.5 \\
\hline 2 & 1.3 & 1.7 & 3 & 6.6 & 14.7 & 15.9 & 3 & 19.2 \\
\hline 3 & 2.6 & 3.0 & 3 & 9.2 & 4.8 & 6.4 & 4 & 11.4 \\
\hline 4 & 6.9 & 5.6 & 4 & 10.8 & 1.8 & 2.4 & 5 & 9.5 \\
\hline 5 & 7.9 & 7.9 & 5 & 13.6 & 0.5 & 0.8 & 6 & 5.8 \\
\hline 6 & 12.2 & 10.4 & 6 & 13.1 & 0.2 & 0.4 & 7 & 3.9 \\
\hline 7 & 12.9 & 11.5 & 6 & 12.1 & 0.0 & 0.1 & 8 & 2.9 \\
\hline 8 & 11.1 & 12.6 & 7 & 9.8 & 0.3 & 0.0 & 9 & 1.7 \\
\hline 9 & 11.9 & 12.6 & 7 & 7.6 & 0.0 & 0.0 & 10 & 0.9 \\
\hline 10 & 9.3 & 11.3 & 8 & 5.6 & 0.0 & 0.0 & 10 & 0.4 \\
\hline 11 & 8.0 & 8.4 & 9 & 3.7 & 0.0 & 0.0 & 10 & 0.0 \\
\hline 12 & 6.9 & 7.5 & 10 & 1.9 & 0.0 & 0.0 & 10 & 0.0 \\
\hline 13 & 3.4 & 5.0 & 10 & 0.8 & 0.0 & 0.0 & 10 & 0.0 \\
\hline 14 & 4.6 & 2.0 & 10 & 0.4 & 0.0 & 0.0 & 10 & 0.0 \\
\hline 15 & 0.8 & 0.9 & 10 & 0.1 & 0.0 & 0.0 & 10 & 0.0 \\
\hline
\end{tabular}

TABLE 11 - CORRELATIONS BETWEEN THE 16PF FACTOR SCORES AND THE VALIDITY SCALES

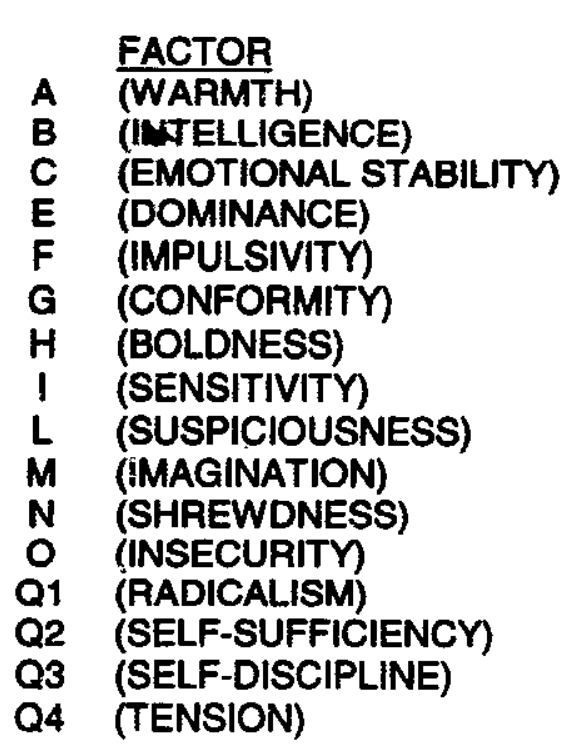

\begin{tabular}{|c|c|c|c|}
\hline \multicolumn{2}{|c|}{ FAKE GOOD (MD) } & \multicolumn{2}{|c|}{ FAKE BAD (FB) } \\
\hline FEMALE & MALE & FEMALE & MALE \\
\hline .15 & .25 & -.06 & -.11 \\
\hline .13 & .02 & -.03 & .04 \\
\hline .56 & .56 & -.24 & -.25 \\
\hline .07 & .06 & .13 & .05 \\
\hline-.13 & -.06 & -.00 & -.04 \\
\hline .43 & .44 & -.07 & -.16 \\
\hline 41 & .47 & -.19 & -.26 \\
\hline-.20 & .01 & -.02 & -.11 \\
\hline-.35 & -.40 & .27 & .25 \\
\hline .11 & .09 & .04 & -.06 \\
\hline .26 & .24 & -.10 & -.09 \\
\hline-.54 & -.56 & .25 & .22 \\
\hline .04 & -.06 & .09 & .09 \\
\hline-.15 & -.24 & .19 & .22 \\
\hline .57 & .55 & -.24 & -.22 \\
\hline-.60 & -.62 & .25 & .23 \\
\hline
\end{tabular}




\section{CONCLUSIONS}

These data support the findings of Karson and O'Dell (1974a) in revealing that female and male ATCS applicants have highly similar personality profiles. Despite a number of changes in the demographic composition of the ATCS applicant groups since the Karson and O'Dell (1974a) study, the basic 16PF profiles are quite similar. Results from current data were generally consistent with prior studies. For example, 1974 ATCS applicants (Karson and O'Dell, $1974 \mathrm{a}, \mathrm{b}$ ) controllers on the job (Karson and O'Dell, 1974 b; Rose, et al., 1978), and applicants in 1984 were found to be brighter than the average individual.

Elevations in scores for several of the other factors were also consistent with previous findings for both controller and applicant groups (Karson and O'Dell, 1974a,b; Rose, et al., 1978). While controllers were less anxious, as evidenced by lower scores on the Tension, Insecurity, and Suspiciousness factors, they had correspondingly higher scores on the Self-Discipline and Emotional Stability factors. They were also more self-reliant and assertive. In his review of research on the aptitudes, interests, motivations, personality, and attirudes of air traffic controllers, Smith (1994) provides a similar description of their salient characteristics.

The higher MD scores for female and male ATCS applicants suggest that the elevations of certain 16PF factors may be partially attributable to the tendency of applicants to present themselves in a favorable light. However, when a correction (IPAT, 1970) for elevated MD scores is applied to the relevant $16 \mathrm{PF}$ factor scores, the overall profile is found to be essentially the same. It is also possible that some vocational objectivity (awareness) or self-selection may be responsible for part of the results, as a person with high levels of anxiety and insecurity is not likely to choose air traffic control as a career option. On the other hand, while social desirability has generally been interpreted to be a situationally-based response set, there are indications (Furnham, 1986) that social desirability may be a relatively stable trait. Ones, Viswesvaran, and Reiss (1996), in their recent metaanalysis of the social desirability literature, support
Furnham (1986) in demonstrating that social desirability has a consistent relationship with the personality dimensions of Emotional Stability and Conscientiousness. Additionally, they found that social desirability is less pervasive than anticipated and exhibits little influence on the relationship between various personality measures and job performance. If this is true, it suggests that the higher MD scores exhibited by the ATCS applicants may be reflective of more positive psychological adjustment in that group.

These results present a positive picrure of ATCS applicants: their intellectual capacity and analytical skills are high; they have sufficient resources to cope with stressful events; and they are assertive enough to make effective decisions.

\section{REFERENCES}

Catrell, R.R. (1949). The Sixteen P.F. Questionnaire (1st ed.). Champaign, IL: Institute for Personality and Ability Testing.

Cobb, B.B., Matthews, J.I., and Lay, C.D. (1972). A comparative study of female and male Air Traffic Controller Trainees. Washington, DC: FAA Office of Aviation Medicine, Report No. FAA-AM-7222. ADA747991.

Cohen, J. (1988). Statistical Power Analysis for the Behavioral Sciences. Hillsdale, NJ: Lawrence Erlbaum and Associates.

Dolgin, D.L., and Gibb, G.D. (1988). A review of personality measurement in aircrew selection. Naval Aerospace Medical Research Laboratory Report. NAMRL Monograph 36, July.

Feingold, A. (1994). Gender differences in personality: A meta-analysis. Psychological Bulletin, 116, 42956.

Furnham, A. (1986). Response bias, social desirability, and dissimulation. Personal and Individual Differences, $7,385-400$.

Harman, H. (1967). Modern factor analysis. Chicago, IL:University of Chicago Press.

Hebbler, S.W. (1989). A basic program for computing the coefficient of concordance, rc. Education and Psychological Measurement, 49, 615-18. 
Howell, D.C. (1987). Statistical methods for psychology. Boston: PWS-Kert Publishing Company.

IPAT (1970). Norms for the 16PF, Forms $A$ and $B$. Tabular Supplement No. 1, (1967-68 Edition), Champaign, IL: Institute for Personality and Ability Testing.

IPAT staff (1986). Administrators manual for the 16 Personality Factor Questionnaire. Champaign, IL: Institute for Personality and Ability Testing.

Karson, S., and O'Dell, J.W. (1974a). Personality differences between $m$ le and female Air Traffic Controller applicants. Aerospace Medicine, 45, 596-8.

Karson, S., and O'Dell, J.W. (1974b). Personality makeup of the American Air Traffic Controller. Aviation Medicine, 45, 1001-7.

Karson, S., and O'Dell, J.W. (1976). A guide to the clinical use of the 16PF. Champaign, IL: Institute for Personality and Ability Testing.

Krug, S.E. (1978). Further evidence on 16PF distortion scales. Journal of Personality Assessment, 42,-513-18.
Krug, S.E. (1981). The I6PF Primer. Champaign, IL: Institute for Personality and Ability Testing.

McGraw, K.O., and Wong, S.P. (1992). A common language effect size statistic. Psychological Bulletin, $111,361-5$.

Ones, D.S., Viswesvaran, C., and Reiss, A.D. (1996). Role of social desirability in personality testing for personnel selection: The red herring. Journal of Applied Psychology, 81, 660-79.

Rose, R.M., Jenkins, C.D., and Hurst, M.W. (1978). Air traffic controller health study. Washington, DC: FAA Office of Aviation Medicine Report, Report No. FAA-AM-78-39. ADA063709.

Smith, R.C. (1994). A realistic view of the people in air traffic control. Washington, DC: FAA Office of Aviation Medicine Report, Report No. FAA-AM74-12. ADA006789.

Winder, P., O'Dell, J.W., and Karson, S. (1975). New motivational distortion scales for the 16PF. Journal of Personality Assessment, 32, 532-7. 


\section{APPENDIX A}

FACTOR A (WARMTH)

\section{LOW SCORE}

RESERVED

DETACHED

CRITICAL

COOL, ALOOF

FORMAL

RIGID
HIGH SCORE

OUTGOING

WARMHEARTED

EASYGOING

PARTICIPATING

LIKES PEOPLE

ADAPTABLE

FACTOR B (INTELLIGENCE)

\section{LOW SCORE}

LESS INTELLIGENT

CONCRETE THINKING
HIGH SCORE

MORE INTELLIGENT ABSTRACT THINKING BRIGHT

FACTOR C (EMOTIONAL STABILITY)

\section{LOW SCORE}

AFFECTED BY FEELINGS

EMOTIONALLY LESS STABLE

EASILY UPSET

WORRYING

\section{HICH SCORE}

EMOTIONALLY STABLE FACES REALITY

CALM

MATURE

UNRUFFLED

FACTOR E (DOMINANCE)

\section{LOW SCORE}

HUMBLE

MILD

ACCOMMODATING

CONFORMING

EASILY LED

OBEDIENT

SUBMISSIVE

\section{HIGH SCORE}

ASSERTIVE

AGGRESSIVE

STUBBORN

COMPETITIVE

BOSSY

DOMINANT

HEADSTRONG 
LOW SCORE

SOBER

PRUDENT

SERIOUS

TACITURN

RESTRAINED

SILENT, INTROSPECTIVE

FACTOR G (CONFORMITY)

LOW SCORE

EXPEDIENT

DISREGARDS RULES

FEELS FEW OBLIGATIONS

SELF-INDULGENT

UNDEPENDABLE

FACTOR H (BOLDNESS)

\section{LOW SCORE}

SHY

RESTRAINED

TIMID

THREAT-SENSITIVE

HESITANT
HIGH SCORE

HAPPY-GO-LUCKY

IMPULSIVELY LIVELY

ENTHUSIASTIC

EXPRESSIVE

TALKATIVE
HICH SCORE

CONSCIENTIOUS

PERSEVERING

STAID

MORALISTIC

RULE BOUND

RESPONSIBLE

HIGH SCORE

VENTURESOME

SOCIALLY BOLD

UNINHIBITED

SPONTANEOUS

RESPONSIVE

FACTOR I (SENSITIVITY)

\section{LOW SCORE}

TOUGH-MINDED

SELF-RELIANT

REALISTIC

NO-NONSENSE

HARD
HIGH SCORE

TENDER-MINDED

CLINGING

OVER-PROTECTED

SENSITIVE

KINDLY, GENTLE

INSECURE 
FACTOR L (SUSPICIOUSNESS)

LOW SCORE

TRUSTING

ADAPTABLE

FREE OF JEALOUSY

EASY TO GET ALONG WITH

PLIANT TO CHANGES
HIGH SCORE

SUSPICIOUS

SELF-OPINIONATED

HARD TO FOOL

SKEPTICAL

DISTRUSTFUL

FACTOR M (IMAGINATION)

\section{LOW SCORE}

PRACTICAL

CAREFUL

CONVENTIONAL

REGULATED BY EXTERNAL REALITIES

PROPER

"DOWN-TO-EARTH" CONCERNS

\section{HIGH SCORE}

IMAGINATIVE

WRAPPED UP IN URGENCIES

CARELESS OF PRACTICAL MATTERS

BOHEMIAN

ABSENT-MINDED

UNCONVENTIONAL

\section{FACTOR N (SHREWDNESS)}

\section{LOW SCORE}

FORTHRIGHT

NATURAL

ARTLESS

UNPRETENTIOUS

OPEN

GENUINE

SPONTANEOUS

\section{HIGHSCORE}

SHREWD

CALCULATING

WORLDLY

PENETRATING

SOCIALLY AWARE

POLISHED

FACTOR O (INSEC'JRITY)

\section{LOW SCORE}

SELF-ASSURED

CONFIDENT

SERENE

FREE OF GUILT

SECURE

COMPLACENT
HICH SCORE

APPREHENSIVE

SELF-REPROACHING

WORRYING

TROUBLED

GUILT-PRONE

LONELY, BROODING 
FACTOR Q1 (RADICALISM)

LOW SCORE

CONSERVATIVE

RESPECTING ESTABLISHED IDEAS

TOLERANT OF TRADITIONAL DIFFICULTIES
HICH SCORE

EXPERIMENTING

LIBERAL

ANALYTICAL

FREE-THINKING

OPEN TO CHANGE

REBELLIOUS

\section{FACTOR Q2 (SELF-SUFFICIENCY)}

\section{LOW SCORE}

GROUP-DEPENDENT

A "JOINER" AND SOUND FOLLOWER

DECISIONS

LISTENS TO OTHERS
HICH SCORE

SELF-SUFFICIENT

PREFERS OWN

RESOURCEFUL

FACTOR Q3 (SELF-DISCIPLINE)

\section{LOW SCORE}

UNDISCIPLINED SELF-CONFLICT

FOLLOWS OWN URGES

CARELESS OF PROTOCOL

UNCONTROLLED

LAX

\section{HIGH SCORE}

CONTROLLED

SOCIALLY PRECISE

FOLLOWING SELF-IMAGE

COMPULSIVE

\section{FACTOR Q4 (TENSION)}

\section{LOW SCORE}

RELAXED

TRANQUIL

UNFRUSTRATED

COMPOSED
HIGH SCORE

TENSE

FRUSTRATED

DRIVEN

OVERWROUGHT

FRETFUL

Descriptive information for the factors was taken from the 16PF test profile (1967), Karson \& O'Dell (1976), and the Administrator's manual for the 16PF (1986). 